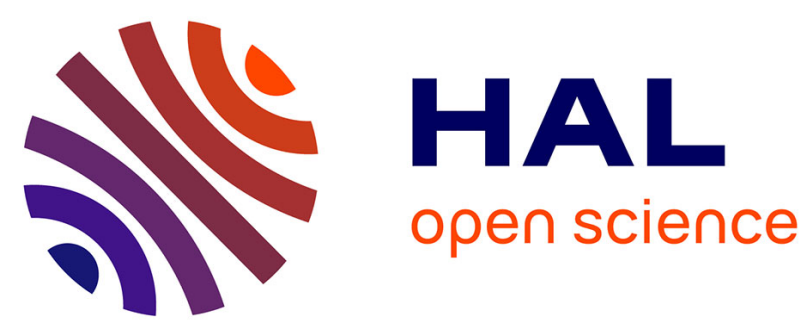

\title{
Fast ultra-deep silicon cavities: Toward isotropically etched spherical silicon molds using an ICP-DRIE
}

Etienne Herth, Maciej Baranski, Djaffar Berlharet, Samson Edmond, David Bouville, Laurie E Calvet, Christophe Gorecki

\section{- To cite this version:}

Etienne Herth, Maciej Baranski, Djaffar Berlharet, Samson Edmond, David Bouville, et al.. Fast ultradeep silicon cavities: Toward isotropically etched spherical silicon molds using an ICP-DRIE. Journal of Vacuum Science \& Technology B, Nanotechnology and Microelectronics, 2019, 37 (2), pp.021206. 10.1116/1.5081503 . hal-02389090

\section{HAL Id: hal-02389090 https://hal.science/hal-02389090}

Submitted on 2 Dec 2019

HAL is a multi-disciplinary open access archive for the deposit and dissemination of scientific research documents, whether they are published or not. The documents may come from teaching and research institutions in France or abroad, or from public or private research centers.
L'archive ouverte pluridisciplinaire HAL, est destinée au dépôt et à la diffusion de documents scientifiques de niveau recherche, publiés ou non, émanant des établissements d'enseignement et de recherche français ou étrangers, des laboratoires publics ou privés. 


\section{Fast Ultra-Deep Silicon Cavities : Toward Isotropically Etched Spherical Silicon Molds using an ICP-DRIE}

Etienne Herth, ${ }^{1,2}$ Maciej Baranski, ${ }^{2}$ Djaffar Berlharet, ${ }^{2}$ Samson Edmond, ${ }^{1}$ David Bouville, ${ }^{1}$ Laurie Calvet, ${ }^{1}$ and Christophe Gorecki ${ }^{2}$

${ }^{1)}$ Centre de Nanosciences et de Nanotechnologies, CNRS UMR 9001, Univ. Paris-Sud, Université Paris-Saclay, C2N-Orsay, 91405 Orsay cedex, France ${ }^{\text {a) }}$

2) FEMTO-ST, Université de Franche Comté, UBFC, CNRS UMR 6174-25044 Besançon cedex, France

(Dated: 28 January 2019)

The paper investigates the parameter optimization of isotropic bulk silicon micro-scale etching using an Inductive Coupled Plasma -Deep Reactive Ion Etching (ICP-DRIE) system. Etch profile characteristics, depending on process and feature size, have been studied. We report detailed observations of the resulting for various etching parameters, covering: pressure from 30 to $70 \mathrm{mTorr}^{\mathrm{SF}_{6}}$ flow rate from 100 to $500 \mathrm{sccm}$, platen power from 20 to $150 \mathrm{~W}$ and ICP power from 2000 to $2500 \mathrm{~W}$. This goal here is to present how anisotropic and isotropic etch processes for a wide range of applications in microfluidics, micro-electro-mechanical-systems (MEMS) and Micro Optoelectronic Mechanical System (MOEMS) fabrication. A deep anisotropic etch through a $1.4 \mathrm{~mm}$ thick silicon wafer with smoothly etched surfaces has been achieved. Isotropic plasma etching is obtained, including a relation between the etching depth, the undercut and the normalized radius of curvature (ROC) of the profile. We have demonstrated an isotropic plasma potential that is much higher than those that can be produced by isotropic wet etching of silicon for the generation of more complex forms such as the manufacturing microlens molds. In particular, we have presented the possibility of creating aspheric shapes with a desirable negative conic constant $(\mathrm{k}<0)$ and a potential high NA numerical aperture. The choice of using photoresist masks provides a better flexibility and economical processing. The presented results can be valuable for a wide range of applications, thus allowing a massive production using only a single commercial ICP DRIE tool, low cost and compatible with an industrial perspective.

\section{INTRODUCTION}

Microsystem technologies are widely used in manufacturing and laboratory research. Today, mainstream microelectronics and microtechnology predominantly use silicon as substrate material. The Inductive Coupled Plasma (ICP) reactor has been thus widely used for anisotropic silicon etching because it is able to obtain a high aspect ratio, while maintaining a vertical side wall ${ }^{1-5}$. Indeed, by Deep Reactive Ion Etching (DRIE) technology, the silicon substrate and III-V compound semiconductors can be etched fairly quickly and manufactured at low cost for mass production ${ }^{6,7}$. This plasma technology is becoming increasingly attractive in a very wide set of applications ${ }^{8-11}$ as well as for microfluidic devices $^{12-14}$, microprobes ${ }^{15}$, microlens molds ${ }^{16-18}$, roll bearing components ${ }^{19}$ and micro-optic structures ${ }^{20}$.

The development of advanced MOEMS and Microfluidic devices demands different shapes with plane, spherical, aspheric and free form surfaces of high profile and excellent surface finish. The design of aspheric surfaces is extremely important in optical systems (eg microlenses) and has been applied in various applications. For instance, in miniaturized systems aspheric surfaces can correct aberrations, improve the image quality and reduce the size and weight of optical systems. Further investigation has been carried out in our laboratory to manufacture microlense molds by wet etching ${ }^{16}$. Isotropic etching of silicon can be obtained by wet chemistry or by plasma etching ${ }^{21}$, however the latter has not gained

\footnotetext{
${ }^{a)}$ Electronic mail: etienne.herth@c2n.upsaclay.fr
}

much attention compared with wet etching the isotropic in both glass ${ }^{22,23}$ and silicon materials. Likewise, silicon wet etching is always used in MEMS during the final stage of the micromachining process, such as the release of the cantilever beam from the substrate ${ }^{24-26}$. Belen et al. have developed a semiempirical feature scale model of $\mathrm{Si}$ etching in $\mathrm{SF}_{6}$ plasma, as well as the effect ion incidence angle ${ }^{27-29}$. The authors have been numerically investigated the relationship between microscale patterns on a Si wafer, the interfacial structure of the plasma and the feature profile of deep-Si etching under plasma. Although the ICP-DRIE technology has been actively studied and published in several articles explaining the effect of etching parameters on the profile, the deep anisotropic etching was generaly limited above $500 \mu \mathrm{m}$ etching depth and hilights the need and demand to preserve the straigth sidewall ${ }^{5,30}$. In micro-optical systems, the elimination of optical aberration can be achieved by using aspherical silicon molds characterized by negative conic constant, however not many micro-fabrication technologies allow arbitrary control of generated geometries of microlenses. To address this issue, our strategy is based on cheaper and improved etching methods. The purpose of this paper is to discuss and to give the details of fast etching and ultra deep silicon $(>1$ $\mathrm{mm}$ ) trenches and as well as its curvated cavities and their properties.

In this respect our motivation is to combine anisotropic and isotropic etch in one DRIE tool. In this article we will present results for various silicon size features as a function of ICP etch processes. This paper is organised as follows: the second section describes the process used to fabricate, characterize and compare various apertures sizes. The third sec- 
tion describes the ICP process for silicon cavities of millimeter range depths. In the fourth section, we investigate the isotropic effect by exploring how the shape of the silicon aperture evolves during the ICP processes. We conclude with a discussion of these investigations and its application to microfluidic, microlense molds, and microsystems through MOEMS and BIOMEMS applications.

\section{FABRICATION AND CHARACTERIZATION METHODS}

The experiments were performed in a Surface Process Technology Systems (SPTS) Rapier tool. It was used with up to $3 \mathrm{~kW}$ of $13.56 \mathrm{MHz}$ power. The temperature of the wafer is controlled using an electro-static chuck. Gases employed in this study were perfluorocyclobutane $\left(\mathrm{C}_{4} \mathrm{~F}_{8}\right)$, sulfur hexafluoride $\left(\mathrm{SF}_{6}\right)$, and oxygen $\left(\mathrm{O}_{2}\right)$ (in sccm, denoting cubic centimeters per minute). An oxygen cleaning was performed between each experiment to remove polymer from the sidewalls of the reactor, minimizing contamination and preserving repeatability. There are numerous important etchant properties, such as etch rate, masking materials, selectivity, surface roughness. Kovacs and al. $^{31}$ have provided a generalized comparison of the various etchants in terms of many of these important properties and the availability of suitable masking films. In this work, different etch processes were studied and their general characteristics were compared. Typical parameters for these processes are presented in Fig. 1 and tabulated in Table I. Standard microfabrication steps followed to obtain test samples are described in Fig. 1.

\section{RESULTS}

\section{A. Anisotropic etch}

In deep silicon etching for microelectromechanical system(MEMS) typical etch depths are generally 10-500 $\mu \mathrm{m}^{32}$. Using the Bosch process, very high aspect ratio trenches of up to $107: 1$ were reported for $374 \mathrm{~nm}$ widths by Marty et al. ${ }^{33}$. More recently, aspect ratios of 160:1 were reported by Parasuraman et al. for trenches of $250 \mathrm{~nm}$ widths ${ }^{34}$. However, for differents MEMS and MOEMS applications, etch depth greater than $500 \mu \mathrm{m}$ are needed. We have targeted $1.4 \mathrm{~mm}$ depths using a mask photoresist (AZ9260) which is suitable and can be deposited with thickness of more than $20 \mu \mathrm{m}$. The DRIE conditions are summarized in Table I. In these experiments, the duty cycle was fixed at $10 \%$ (see Fig.2), its effect is important on the etching process and profile, while varying the other parameters. This pre-test shown in Table I, is focused on the coupling effect of the gas mixture, the source power and the pressure on the etching rate and profile (see Fig.2b).

As expected, it becomes evident that the etch rates are monotonically decreased with decreasing aperture size as seen in Fig.2a. This is the so-called "Aspect Ratio Dependent Etching" (ARDE) effect. The results of the etch profiles are carefully analyzed by the isotropic ratio ${ }^{35}, A_{F}$ defined as:

$$
A_{F}=1-\frac{r_{\text {lat }}}{r_{\text {vert }}}
$$

where $r_{\text {lat }}$ is either the horizontal dimension of the foot edge from the mask edge or the undercut rate and $r_{\text {vert }}$ is either the vertical etched depth or the etch rate as illustrated in Fig.3.

Fig. 4 shows a selection of the sidewall profiles that have been obtained in our experiments. These SEMs clearly demonstrate that it is difficult to obtain a straightforward definition of the anisotropy. Indeed, depending on the process parameters, the profiles may vary from ideal isotropy. No significant amount of undercut was observed using the recipe 1a, which results in an anisotropy value of 1 indicating a perfect vertical sidewall with no mask undercut. Previously, good results of ultra-deep silicon cavities with smooth sidewalls, using an Alcatel DRIE reactor tool, have been reported ${ }^{36}$ with etch rate around to $5 \mu \mathrm{m} / \mathrm{min}$. However, based on the recipe 1 results, the relative etch rate with the same design rule, the rate process is higher and close to $11 \mu \mathrm{m} / \mathrm{min}$ with a scalloping of around $250 \mathrm{~nm}$. A consequence of the pulsed DRIE process with this high etch rate is improved cost, efficiency and yield of the microfabrication devices. Mastering deep etching technologies has enabled manufacturing and to miniaturization of the atomic-clock and magnetometer as highlighted in Fig.4.

Nevertheless, to completely etch through a $1.4 \mathrm{~mm}$ thick silicon wafer suffers the intrinsic disadvantage of scalloped sidewalls and high sidewall surface roughness. For instance, the process needs to be

one tuned for every aperture size during the same step. Recipe 1a consists of alternating isotropic etching under $\mathrm{SF}_{6}$ plasma and passivation using the $\mathrm{C}_{4} \mathrm{~F}_{8}$ plasma. When silicon is being etched using this Bosch process, silicon grass, due to the residual passivation layer, is formed at the bottom of the holes as etching by-products. If the passivation layer, after $\mathrm{C}_{4} \mathrm{~F}_{8}$ deposition, is not completely removed, it makes a micromask. Silicon grasses are thus undesirable by-products in micro-devices. To overcome these drawbacks, optimized recipe processes are presented in more detail in Table II. Besides three recipes presented in Table I, gradual increase of process ecthing time on several etch steps using presented $\mathrm{SF}_{6} / \mathrm{C}_{4} \mathrm{~F}_{8}$ as well as other parameter (pressures, power) presented in Table II, proves that this approach has many special advantages e.g., smooth trench sidewall, high etch rate and selectivity. Table II and Fig.5 present the results for these trenches. No mask undercut was observed using recipe 1a and $1 \mathrm{~b}$, the surface scalloping inherent to the bosch process were around to $200 \mathrm{~nm}$. The chamber pressure principally affects the mean free path (MFP) of an ion in the plasma, with lower pressures providing longer paths and thus higher energy ions. Finally, we observed in Fig.5 that the etch rates were nonlinear. One of the significant issues in this etch is the ARDE (Aspect Ratio Dependent Etch). The silicon etch rate depends on the mask opening size. In particular, the smallest mask opening was etched the slowest.

The etch profile appears straight and with smooth sidewall. With revised recipe $1 \mathrm{~b}$, we have successfully etched trenches as narrow as $10 \mu \mathrm{m}$ for $55 \mu \mathrm{m}$ depth and as wide as $1100 \mu \mathrm{m}$ 
for $117 \mu \mathrm{m}$ depth. The performance shows for this method a good application potential for the production of microelectronic and MOEMS, and MEMS in particular, to completely etch through a thicker silicon wafer (more than $500 \mu \mathrm{m}$ ). The reported process was employed to fabricate cells for miniature atomic clocks ${ }^{37}$.

Moving on towards less vertical (anisotropic)etch processes, the continuous process using a $\mathrm{S} F_{6} / \mathrm{O}_{2}$ plasma seems to be the best compromise between straigth sidewall and complete curvated shaped. Nevertheless, $\mathrm{SF}_{6} / \mathrm{O}_{2}$ gas chemistry tends to generate bowing in silicon ${ }^{38}$. Although the fabrication of the tapered through silicon vias by $\mathrm{SF}_{6} / \mathrm{O}_{2}$ and $\mathrm{SF}_{6} / \mathrm{O}_{2} /$ Ar plasma has been reported ${ }^{38,39}$, the effect of $\mathrm{SF}_{6} / \mathrm{O}_{2} / \mathrm{C}_{4} \mathrm{~F}_{8}$ chemistry on both the slope angle and roughness has not been provided. Recipe 2 resulted in an anistropy close to $0.7 @ 70$ mTorr. In fact, at high $\mathrm{O}_{2}$ pressures, the value of the anisotropy, as defined before, may be lower because of outward by sloping etch profiles. This gas chemistry provided an overall etching rate about $7 \mu \mathrm{m} / \mathrm{min}$, a roughness lower than $200 \mathrm{~nm} @ 70$ mTorr and a tapered profile with sidewall angles between $55-70^{\circ}$.

A similar technology using a continuous process with a pure $\mathrm{SF}_{6}$ plasma to create a spherical cavity has been reported, but the geometrical parameters of the etched cavities has not been provided in detail. The study of the undercut and the curvature profile, in the case of an anisotropy factor close to 0 (recipe 3 ) is considered in more depth in the next section.

\section{B. Isotropic etch}

Even though wet silicon etch can have an aspect ratio as high as 600 , this deep anistropic etch technique by aqueous solutions is inherently limited to the fabrication of structures such as microlenses mold (see Fig.6) where the isotropic effect is desired. In recent years, much effort has been placed on further improving isotropic wet etching ${ }^{16,40}$ and in isotropic dry etching ${ }^{17-19}$. Consequently, the spherical cavity size was found to depend mostly on the size of the etch-mask opening, and be independent of the etching time. A variety of mask materials and etching conditions were investigated to obtain a large spherical cavity $(2.5 \mathrm{~mm}$ in radius) with good circularity and smoothness. Early works focused on microlenses, which were specifically developed for different MOEMS applications ${ }^{16,20,41}$. Previous reports on isotropic dry etching technology have been documented ${ }^{17,19}$ showing that the anisotropic plasma can be optimized, when the mask opening and the process parameter are matched, to produce a sphere shape (Fig.6). Here, we considered different size of circular mask openings ( ranging from $20 \mu \mathrm{m}$ to $600 \mu \mathrm{m}$ ). The $\mathrm{SF}_{6}$ flow rate was increased at $500 \mathrm{sccm}$ and pressure from $40 \mathrm{mTorr}$ to $150 \mathrm{mTorr}$. The isotropic chemical etching of $\mathrm{F}^{*}$ radicals caused the lateral etching, which resulted in the sideways undercut.

Fig.7 shows mask undercut and etch depth as a function of mask opening diameter. The results show that for all the test structures analyzed, the etch rate increased quite significantly with increasing pressure. The undercut and the etch depth are found to increase with mask opening, but tends to saturate between $350 \mu \mathrm{m}$ to $600 \mu \mathrm{m}$ diameters, which indicates that the silicon etch rate is principally limited by the availability of fluorine radicals at the silicon substrate.

At high pressure, the non-uniformity of etch depth was observed. This could be attributed in large part to the limitations of the pumping system of the ICP reactor, which plays an increasingly important role in the uniformity of species diffusion inside the reactor. Fig. 8 shows that for different mask openings, the degree of anisotropic etching given in equation 1 is between 0.2 to 0.4 whatever the pressure. Increasing the pressure should increase the atomic fluorine concentration and decrease the ion bombardment. Both effects lead to a reduction of the anisotropy, in agreement with our results at high pressures (100 mTorr and 150 mTorr). However, at $500 \mathrm{sccm}$ $\mathrm{SF}_{6}$ flow rate, the etch rate and undercut rate were saturated because of (a)the recombination of radicals before reaching the sample surface and /or (b) insufficient source power (2000 W) to promote the dissociation of $\mathrm{SF}_{6}$ and produce fluorine radicals.

These results show that the physical etching rate in the vertical direction increased faster than in horizontal direction when the pressure was higher than 40 mTorr. SEM of cleaved samples was utilized to confirm the degree and the profile of this anisotropic measurements.

Fig.9 shows SEM micrographs of the etched surface taken with a $45^{\circ}$ tilt for wafers etched at 40 mTorr, 100 mTorr and 150 mTorr pressure. These results show that surface roughness decreases significantly at lower pressure. Clearly, as presented in Fig.10, the curvature of the cavity is variable and depends on the mask opening and the fabrication process. For larger opening masks, the profiles show a very flat center region. As a consequence, the degree of anisotropic etching is a good indicator and must be completed by SEM view or by interferometry measurement.

Nevertheless, spherical profile measurements are more difficult than flat surfaces. The more complex geometries are often described as conic sections that can be expressed by the following equation :

$$
Z(r)=\frac{c r^{2}}{1+\sqrt{1-(k+1) c^{2} r^{2}}}+\sum_{i=n_{0}}^{N} \alpha_{i} r^{i}
$$

where $\mathrm{r}$ is the radial coordinate, $\mathrm{c}$ is vertex curvature, $\alpha_{i}$ are the polynomials coefficients. This formulation is used in geometric optics to specify oblate elliptical $\mathrm{k}>0$, spherical $\mathrm{k}=0$, prolate elliptical $0<\mathrm{k}<-1$, parabolic $\mathrm{k}=-1$, and hyperbolic $\mathrm{k}<-1$. When the paraxial approximation is valid, the optical surface can be treated as a spherical surface with the same radius.

The normalized conic constant $\mathrm{k}$ and the radius of curvature (ROC) of the profiles ${ }^{42}$ were analyzed by fitting a sphere to the bottom part of the silicon cavities.

As expected, the mask opening data (see Fig.11 and Fig.12) and the conic constant $\mathrm{k}$ suggest that a mask opening of $10 \mu \mathrm{m}$ to $210 \mu \mathrm{m}$ allows a semi-circular cross-section and was therefore selected as the opening for future isotropic etching experiments for microlense molds. For larger openings masks, the 
ROC is higher due to the flat profile. The surface roughness increased with change in chamber pressure and was affected significantly for the largest opening masks. Furthermore, in the literature, the roughness, the size aperture and the cavity depth are spread over a wide range according to the mask opening, the process parameters and the etching time. One example of these results is summarized in Table III.

Compared with the microlenses molds ${ }^{17}$ and microballbearing mold ${ }^{19}$ as is shown in Table III, the smallest opening masks showed much low roughness. The RMS is higher than the respective values reported in ${ }^{19}$ due to the higher pressure and larger mask openings used in this work. Larsen et al. ${ }^{17}$ highlighted the role of platen temperature ranging from $0{ }^{\circ} \mathrm{C}$ to $40^{\circ} \mathrm{C}$, in making the radius of curvature of the profile, also showing the effect of the coil and platen power and pressure, however the mask opening was $<65 \mu \mathrm{m}$. The general trends observed can be summarized as: increased plate power reduces the roughness. Low coil power improves sphericity, but reduces the cavity depth and uniformity. Hanrahan et al. ${ }^{19}$ reported a methodology to obtain the circular bearing crosssections by $\mathrm{SF}_{6}$ plasma-based etching; Herein, the strategy was based on a two step isotropic etch. The bulk of the material is removed in the first etch and the depth and curvature are almost fully realized. The second etching step is used to remove the reentrant silicon from beneath the masking material, ultimately widening the raceway and slightly affecting the curvature with lower roughness. However they did not elaborate on the effect of any process parameters on the geometrical characteristics of the spherical profile $(\mathrm{k})$.

Compared with other common isotropic etching using ICP, our data suggests that an opening up to $200 \mu \mathrm{m}$ would be able to give a semi-circular mold. As the cavity gets smaller, ROC decreases rapidly until a minimum is reached. The profile obtained by SEM imaging (Fig. 9b), with a diameter of $100 \mu \mathrm{m}$ reveals that the structure can be described by conic section $\mathrm{k}$ $=0.18$, and $\mathrm{ROC}=55.5 \mu \mathrm{m}$ at 100 mTorr. With such negative conic constants are highly desirable for the fabrication, for instances, of micro-optical scanners ${ }^{20}$.

\section{DISCUSSION}

During this DRIE study, we have investigated both anisotropic and isotropic etching processes: anisotropic etching to achieve depth, and isotropic etching in order to obtain the desired spherical shape. There are many parameters in the processing: pressure, coil power/ platen power, etch/passivation time ratio, flow rate of etch/passivation gas, temperature. The effect of process parameters is already well known.

The reason behind choosing chuck temperature as $0^{\circ} \mathrm{C}$ was for improving the mask selectivity of the UV photoresist. When the temperature increases, the rate of $\mathrm{C}_{x} \mathrm{~F}_{y}$ species desorption increases, leading an overall decrease in polymer deposition rate during the passivation cycle and reducing the risk of the silicon-grass formation. Thus, at $0{ }^{\circ} \mathrm{C}$, the pressure was lower (30 up to 40 mTorr) to reduce the rate depositon of the passivation layer, with the adapted times of the deposition cycle (to preserve a good sidewall and slope angle) and the ion bombardement cycle (to remove all passivation on the silicon surface). Low process pressure (Recipe 1a, $\mathrm{SF}_{6} @ 30 \mathrm{mTorr}$ ) is beneficial for high-aspect ratio etching as presented in Fig.2.a, as exchange of species in narrow deep trenches is accelerated by the higher mean-free path of the gas molecules and radicals. Recipe $1 \mathrm{~b}$ is a trade-off with higher etch rate $(15 \mu \mathrm{m} / \mathrm{min})$ requirements, where the etch rate increases with higher pressure levels $\left(\mathrm{SF}_{6} @ 70\right.$ mTorr). For a deeper etching (up to $1.4 \mathrm{~mm}$ ), both proposed anisotropic processes (slope angle close to $90^{\circ}$ ) are suitable in order to prevent undesirable etching side effects, such as undercut or bowing and $\mathrm{Si}$ grasses. However, Equation 1 does not give information whether the anisotropy is due to mask undercut, to the Bosch process above-mentioned parameters or the sloped profiles. The $\mathrm{SF}_{6} / \mathrm{O}_{2}$ chemistry (recipe 2, Table I) has an ioninhibitor process where $\mathrm{SF}_{6}$ breaks into $\mathrm{SF}_{5}^{+}, \mathrm{e}^{-}$and $\mathrm{F}^{*}$ radicals. The oxygen reacts with silicon and $\mathrm{SF}_{5}^{+}$and forms protecting $\mathrm{Si}_{x} \mathrm{O}_{y}$ and $\mathrm{Si}_{x} \mathrm{O}_{y} \mathrm{~F}_{z}$ layers on the via sidewalls. While, the $\mathrm{F}^{*}$ radicals etch the silicon by isotropic chemical etching, resulting in tapered slope (see Fig. 4). The sideways undercut increases with the $\mathrm{SF}_{6}$ flow rate (@500sccm). With a careful optimized ratio of $\mathrm{SF}_{6} / \mathrm{O}_{2}$, vias with a continuous tapering profile are formed. The addition of $\mathrm{C}_{4} \mathrm{~F}_{8}(100 \mathrm{sccm})$ is very effective inducing also a sidewall protection, increase the selectivity when using photoresist masks, and promotes a smooth surface morphology (@40 mTorr).

The recipe 2 is a promise to manufacture tapered vias (with a slope angle of $55-70^{\circ}$ ) for 3D interconnections and/or MEMS packaging ${ }^{43}$ as seen in Table I and Fig. 4, using a continuous $\mathrm{SF}_{6} / \mathrm{C}_{4} \mathrm{~F}_{8} / 0_{2}$ plasma chemistry (@ 70 mTorr) with a selectivity of 82:1. For microfluidic applications vias with tapered sidewall can be used as diffuser or nozzle. Moreover, the ICP isotropic etching technology provides an excellent alternative to release microcantilever beams and other suspended design from silicon substrate with low cost and one tool. But, in pure $\mathrm{SF}_{6}$ plasma chemistry (up to 150 mTorr), the manufacturing of microchannels with spherical cavity has obvious advantages such as simple geometry for calculation of the flow rate and the volume of aquaeuous solution injected ${ }^{44}$. However, spherical profile measurements are more difficult than flat surfaces.

Herein, we show that the proposed investigation, in conjunction with other characterizations tools, is therefore able to predict the curvature according to the mask aperture designed and paramater process. This in turn allows using the semi-analytical solution as a very fast solver in analyzes of results. Thus, this approach plays an essential role for the particular design for replication of microfluidic systems. Further research will be forthcoming for the manufacturing of microlenses where the lower roughness and spherical curvature are essential for optimal functioning.

For the past few years, many efforts have been made to study the structures in the Bosch. We demonstrate here :

- Various demands on mask selectivity, etch rate and profile can be met in the fabrication of the silicon based on this starting point recipes.

- Fast and ultra deep etching realised at reasonably high 
etch rates.

- A baseline for controlling the profile of anisotropic silicon manufacturing and / or isotropic processes open a wide area of applications with one tool.

Silicon dioxide, metal masks, or even photoresist (eg AZnLOF 2020, SPR220, AZ9260) are commonly used. We propose to use a photoresist mask that is low cost approach and uses equipment, widespread in the microelectronics laboratories and industry. Nevertheless, the microfabrication route is time consuming. Alternative methods have been commercialized using a dry laminated film photoresists, which are cheaper than spin-on liquid photoresists. Latter can be easly using in our proposed dry etching process.

In this work, the performed experiments were based on the anisotropic plasma toward isotropic plasma etching in order to investigate the fast ultra-deep silicon cavities of the plasma process using an ICP-DRIE but also to determine the range of structures that could be also fabricated toward isotropical plasma. Through the isotropic plasma, we demonstrated a clear potential of this technique for the generation of more complex shapes than the ones that can be produced by wetetching based techniques. In particular, we presented the possibility of creating aspherical shapes with desirable negative conic constant and high aspect ratio (and consequently high Numerical aperture NA of corresponding optical elements).

\section{v. CONCLUSIONS}

A commercially available modern plasma etch system in high frequency $(13.5 \mathrm{MHz})$ has been investigated for best performance, with respect to the design goal. It demonstrated stable and good reliability of isotropic etching by ICP-DRIE for MEMS and MOEMS applications. A cycling and a continuous plasma etching process using respectively $\mathrm{SF}_{6} / \mathrm{C}_{4} \mathrm{~F}_{8}$, $\mathrm{SF}_{6} / \mathrm{C}_{4} \mathrm{~F}_{8} / \mathrm{O}_{2}$ and pure $\mathrm{SF}_{6}$ gases for manufacturing vertical trenches, tapered vias, and spherical shapes, were analyzed. A trade-off between profile and feature size can usually be found quite easily. The anisotropic silicon etch rates in ICPDRIE reactor can reach $15 \mu \mathrm{m} / \mathrm{min}$. Empirical models, which fit very well with the experimental data, were proposed. These can serve for design rules in microelectronics, optoelectronics laboratories and industry. This study opens large scale applications which require high etch rate and stable process, controllable profile, surface properties and low costs. We investigated the possibility to generate larger spherical shapes or structures characterized by negative conic constants that are difficult to make by use of wet etching techniques. A combination of different plasma parameters have been studied and the related ICP recipes can prove useful for optoelectronic, microelectronic and microsystem applications.

\section{ACKNOWLEDGMENTS}

This work was partly supported by the French RENATECH network with FEMTO-ST and C2N technological facilities.
${ }^{1}$ M. Mita, Y. Mita, H. Toshiyoshi, and H. Fujita, IEEJ Transactions on Sensors and Micromachines 120, 493-497 (2000).

${ }^{2}$ S. C. Chen, Y. C. Lin, J. C. Wu, L. Horng, and C. H. Cheng, Microsyst. Technol. 13, 465-474 (2006).

${ }^{3}$ Y. Mita, M. Kubota, T. Harada, F. Marty, B. Saadany, T. Bourouina, and Tadashi Shibata, J. Micromech. Microeng. 16, S135 (2006).

${ }^{4}$ J. Ohara, Y. Takeuchi, and K. Sato, J. Micromech. Microeng. 19, 095022 (2009).

${ }^{5}$ V. M. Donnelly and A. Kornblit, J. Vac. Sci. Technol., A 31, 050825 (2013).

${ }^{6}$ H. V. Jansen, M. J. d. Boer, S. Unnikrishnan, M. C. Louwerse, and M. C. Elwenspoek, J. Micromech. Microeng. 19 (2009).

${ }^{7}$ P. B. Vigneron, F. Joint, N. Isac, R. Colombelli, and E. Herth, Microelectron. Eng. 202, 42-50 (2018).

${ }^{8}$ H. Lavasani, R. Abdolvand, and F. Ayazi, IEEE Trans. Ultrason., Ferroelectr. , Freq. Control 62, 802-813 (2015).

${ }^{9}$ E. Herth, L. Valbin, F. Lardet-Vieudrin, and E. Algré, Microsyst. Technol. , 1-8 (2015).

${ }^{10}$ Z. Xiong, E. Mairiaux, B. Walter, M. Faucher, L. Buchaillot, and B. Legrand, Sensors 14, 20667-20686 (2014).

${ }^{11}$ J. Rutkowski, W. Fourcault, F. Bertrand, U. Rossini, S. Gétin, S. Le Calvez, T. Jager, E. Herth, C. Gorecki, M. Le Prado, J. Léger, and S. Morales, Sens. Actuators, A 216, 386-393 (2014).

${ }^{12}$ H. Berthet, J. Jundt, J. Durivault, B. Mercier, and D. Angelescu, Lab Chip 11, 215-223 (2011).

${ }^{13}$ S. Petralia, G. Panvini, and G. Ventimiglia, BioNanoSci. 5, 150-155 (2015).

${ }^{14}$ M. J. d. Boer, R. W. Tjerkstra, J. W. Berenschot, H. V. Jansen, G. J. Burger, J. G. E. Gardeniers, M. Elwenspoek, and A. v. d. Berg, J. Microelectromech. Syst. 9, 94-103 (2000).

${ }^{15}$ J. Marzouk, S. Arscott, A. El Fellahi, K. Haddadi, C. Boyaval, S. Lepilliet, T. Lasri, and G. Dambrine, Sens. Actuators, A 238, 51-59 (2016).

${ }^{16}$ J. Albero, L. Nieradko, C. Gorecki, H. Ottevaere, V. Gomez, H. Thienpont, J. Pietarinen, B. Päivänranta, and N. Passilly, Opt. Express 17, 6283-6292 (2009).

${ }^{17}$ K. P. Larsen, J. T. Ravnkilde, and O. Hansen, J. Micromech. Microeng. 15, 873 (2005).

${ }^{18}$ K. P. Larsen, D. H. Petersen, and O. Hansen, J. Electrochem. Soc. 153, G1051-G1058 (2006).

${ }^{19}$ B. Hanrahan, C. M. Waits, and R. Ghodssi, J. Micromech. Microeng. 24, 015021 (2014).

${ }^{20}$ J. Lullin, S. Bargiel, P. Lemoal, S. Perrin, J. Albero, N. Passilly, Luc Froehly, F. Lardet-Vieudrin, and C. Gorecki, J. Micromech. Microeng. 25, 115013 (2015).

${ }^{21}$ T. Zhu, P. Argyrakis, E. Mastropaolo, K. K. Lee, and R. Cheung, J. Vac. Sci. Technol., B 25, 2553-2557 (2007).

${ }^{22}$ C. Iliescu, J. Jing, F. E. H. Tay, J. Miao, and T. Sun, Surf. Coat. Technol. 198, 314-318 (2005).

${ }^{23}$ E. Herth, N. Rolland, and T. Lasri, IEEE Antennas Wirel. Propag. Lett. 9, 934-937 (2010).

${ }^{24}$ V. Agache, E. Quévy, D. Collard, and L. Buchaillot, Appl. Phys. Lett. 79, 3869-3871 (2001).

${ }^{25}$ E. Herth, F. Lardet-Vieudrin, L. Valbin, and G. Lissorgues, in 2016 Symposium on Design, Test, Integration and Packaging of MEMS/MOEMS (DTIP) (IEEE, 2016) pp. 1-4.

${ }^{26}$ E. Herth, F. Lardet-Vieudrin, F. Deux, L. Valbin, E. Algré, J. Schell, and H. Steger, in 2016 Symposium on Design, Test, Integration and Packaging of MEMS/MOEMS (DTIP) (2016) pp. 1-4.

${ }^{27}$ R. J. Belen, S. Gomez, M. Kiehlbauch, D. Cooperberg, and E. S. Aydil, J. Vac. Sci. Technol., A 23, 99-113 (2005).

${ }^{28}$ R. J. Belen, S. Gomez, M. Kiehlbauch, and E. S. Aydil, J. Vac. Sci. Technol., A 24, 2176-2186 (2006).

${ }^{29}$ S. Gomez, R. Jun Belen, M. Kiehlbauch, and E. S. Aydil, J. Vac. Sci. Technol., A 22, 606-615 (2004).

${ }^{30}$ Z. Ouyang, D. N. Ruzic, M. Kiehlbauch, A. Schrinsky, and K. Torek, J. Vac. Sci. Technol., A 32, 041306 (2014).

${ }^{31}$ G. T. A. Kovacs, N. I. Maluf, and K. E. Petersen, Proc. IEEE 86, 15361551 (1998).

${ }^{32}$ D. Galayko, A. Kaiser, L. Buchaillot, B. Legrand, D. Collard, and C. Combi, J. Micromech. Microeng. 13, 134 (2003). 
${ }^{33}$ F. Marty, L. Rousseau, B. Saadany, B. Mercier, O. Français, Y. Mita, and T. Bourouina, Microelectron. J. European Micro and Nano SystemsEMN 2004, 36, 673-677 (2005).

${ }^{34}$ J. Parasuraman, A. Summanwar, F. Marty, P. Basset, D. E. Angelescu, and T. Bourouina, Microelectron. Eng. 113, 35-39 (2014).

${ }^{35}$ R. Legtenberg, H. Jansen, M. d. Boer, and M. Elwenspoek, J. Electrochem. Soc. 142, 2020-2028 (1995).

${ }^{36}$ R. K. Chutani, M. Hasegawa, V. Maurice, N. Passilly, and C. Gorecki, Sens. Actuators, A 208, 66-72 (2014).

${ }^{37}$ V. Maurice, J. Rutkowski, E. Kroemer, S. Bargiel, N. Passilly, R. Boudot, R. Chutani, S. Galliou, C. Gorecki, L. Mauri, and M. Moraja, in 2017 Joint Conference of the European Frequency and Time Forum and IEEE International Frequency Control Symposium (EFTF/IFCS) (2017) pp. 636637.

${ }^{38}$ P. Dixit, S. Vähänen, J. Salonen, and P. Monnoyer, ECS J. Solid State Sci. Technol. 1, P107-P116 (2012).
${ }^{39}$ R. Li, Y. Lamy, W. F. A. Besling, F. Roozeboom, and P. M. Sarro, J. Micromech. Microeng. 18, 125023 (2008).

${ }^{40}$ Z. Yifan, C. Sihai, S. Edmond, and A. Bosseboeuf, Jpn. J. Appl. Phys. 52, 076503 (2013).

${ }^{41}$ J. Albero, S. Perrin, S. Bargiel, N. Passilly, M. Baranski, L. GauthierManuel, F. Bernard, J. Lullin, L. Froehly, J. Krauter, W. Osten, and C. Gorecki, Opt. Express 23, 11702-11712 (2015).

${ }^{42}$ D. G. Abdelsalam, M. S. Shaalan, M. M. Eloker, and D. Kim, Opt. Lasers Eng. 48, 643-649 (2010).

${ }^{43}$ H.-D. Ngo, A. Hiess, V. Seidemann, D. Studzinski, M. Lange, J. Leib, Dzafir Shariff, H. Ashraf, M. Steel, L. Atabo, and J. Reast, J. Phys.: Conf. Ser. 34, 271 (2006).

${ }^{44}$ J. Chung, C. P. Grigoropoulos, and R. Greif, Rev. Sci. Instrum. 74, $2911-$ 2917 (2003). 
TABLE I. Different etch processes.

\begin{tabular}{|ll|ccc|}
\hline Parameters & & Recipe 1a & Recipe 2 & Recipe 3 \\
\hline Pressure & (mTorr) & 30 & 40 & 40 \\
Coil Power & (Watts) & 2500 & 2200 & 2000 \\
Platen Power & (Watts) & 20 & 20 & 20 \\
Flow rate $S F_{6}$ & $(\mathrm{sccm})$ & 400 & 500 & 500 \\
Flow rate $O_{2}$ & $(\mathrm{sccm})$ & - & 80 & - \\
Flow rate $C_{4} F_{8}$ & $(\mathrm{sccm})$ & 300 & 100 & - \\
Chuck temperature & $(\mathrm{C})$ & 0 & 0 & 0 \\
Mask Opening & $(\mu \mathrm{m})$ & 300 & 480 & 95 \\
Undercut & $(\mu \mathrm{m})$ & 1 & 100 & 52.4 \\
Etch rate & $(\mu \mathrm{m} / \mathrm{min})$ & 11 & 7 & 8 \\
Selectivity & & $158: 1$ & $82: 1$ & $37: 1$ \\
Anisotrist & $(\mu \mathrm{m})$ & 1 & 0.7 & - \\
Etch Profile & & Vertical & Directional & Isotropic \\
\hline
\end{tabular}

TABLE II. Optimized Bosch process parameters for etching silicon by ICP-DRIE.

\begin{tabular}{|cl|ccc|}
\hline Recipe & Parameters & Passivation & Ion Bombardement & Etch \\
\hline & Process Time (s) & $1.2-1.5$ & $1.3-1.5$ & 2.5 \\
& Pressure (mTorr) & 40 & 30 & 30 \\
Recipe 1a 19 & Coil Power (Watts) & 2500 & 2500 & 2500 \\
& Platen Power (Watts) & 20 & 50 & 20 \\
& Flow rate $S F_{6}(\mathrm{sccm})$ & - & 400 & 400 \\
& Flow rate $C_{4} F_{8}(\mathrm{sccm})$ & 330 & - & - \\
\hline Process Time (s) & $1.5-1.8$ & $1.5-2$ & 3 \\
& Pressure (mTorr) & 30 & 50 & 70 \\
Recipe 1b $1 \mathrm{~b}$ Coil Power (Watts) & 2500 & 2500 & 2500 \\
& Platen Power (Watts) & 20 & 150 & 25 \\
& Flow rate $S F_{6}(\mathrm{sccm})$ & - & 450 & 450 \\
Flow rate $C_{4} F_{8}(\mathrm{sccm})$ & 300 & - & - \\
\hline
\end{tabular}

TABLE III. Discussion and comparison between our work and previous research to manufacture the mold silicon by using a ICP-DRIE reactor.

\begin{tabular}{|ll|ccc|}
\hline Reference & & Our work & $\left.{ }^{17}\right]$ & {$\left[{ }^{19}\right]$} \\
\hline Photoresist mask & & AZ9260 & NC & AZ9260 \\
Mask Opening & $(\mu \mathrm{m})$ & $20-600$ & $7-62$ & $100-200$ \\
Chamber pressure & $(\mathrm{mTorr})$ & $40-150$ & $10-70$ & $17-27$ \\
Coil Power & $($ Watts $)$ & 2000 & $1000-3000$ & 850 \\
Platen Power & $($ Watts) & 20 & $0-16$ & $6-16$ \\
Flow rate $S F_{6}$ & $(\mathrm{sccm})$ & 500 & $200-300$ & 100 \\
Flow rate $\mathrm{Ar}$ & $(\mathrm{sccm})$ & - & - & 40 \\
Flow rate $O_{2}$ & $(\mathrm{sccm})$ & - & $0-30$ & - \\
Chuck temperature & $(\mathrm{C})$ & 0 & $0-40$ & 30 \\
Etch time & $(\mathrm{s})$ & 900 & $300-750$ & $120-300$ \\
Cavity depth & $(\mu \mathrm{m})$ & $27-290$ & $28.6-100$ & $75-260$ \\
ROC & $(\mu \mathrm{m})$ & $0.12-4$ & $0.41-1.15$ & $0.02-0.14$ \\
\hline
\end{tabular}



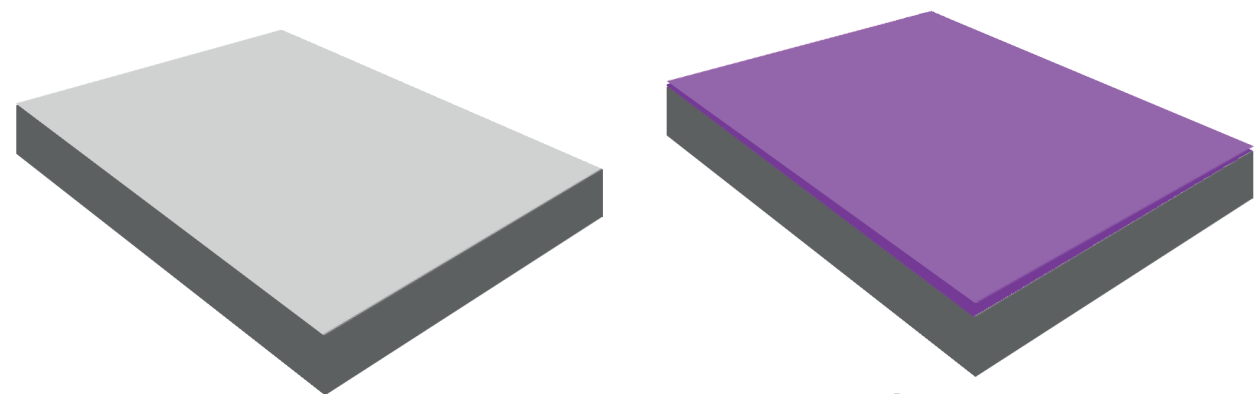

a) Silicon wafer

b) Spin Coating
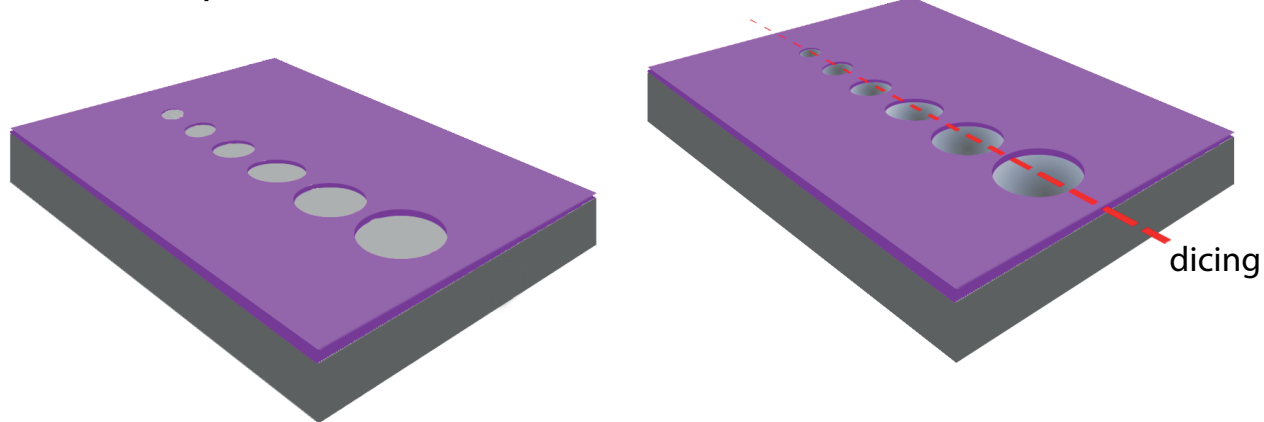

c) Photolithography

d) Dry etching

FIG. 1. Flow chart of the fabrication process for the silicon microlens mold : silicon wafer, b) spin coating photoresist, c) photolithography and d) dry ecthing.
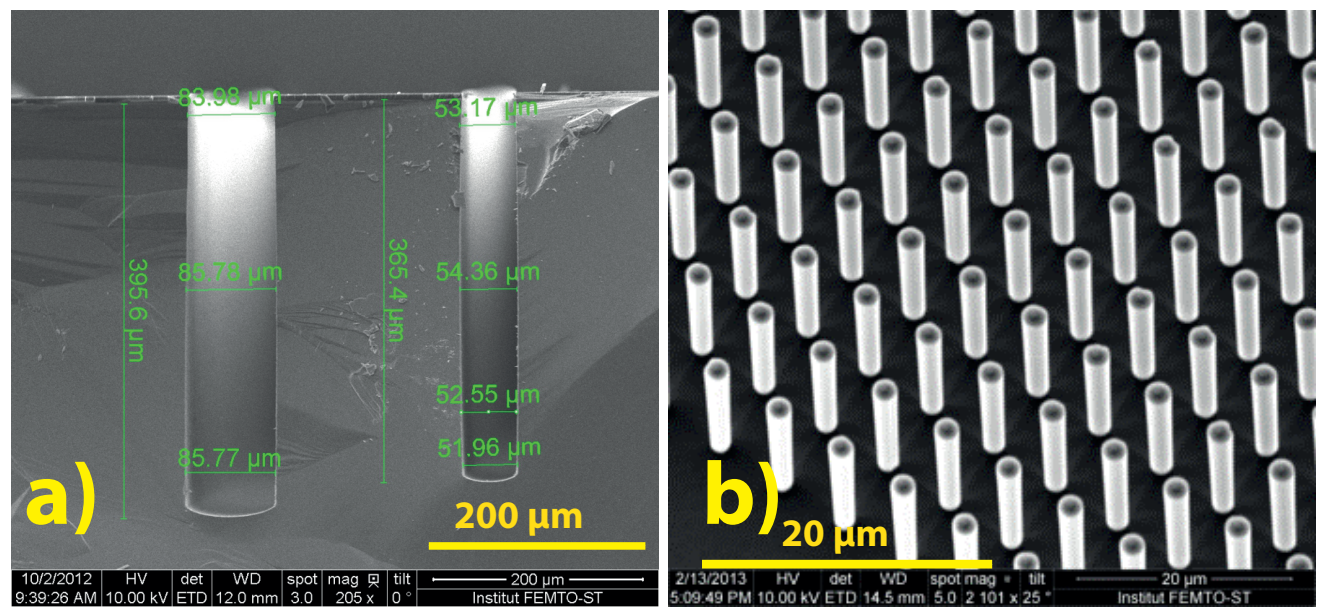

FIG. 2. SEM views of typical results of a) trenches and b) pillars etched in pulsed-mode DRIE. 


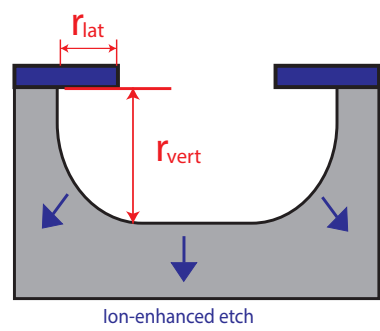

$0 \longleftarrow A_{F}$

a)

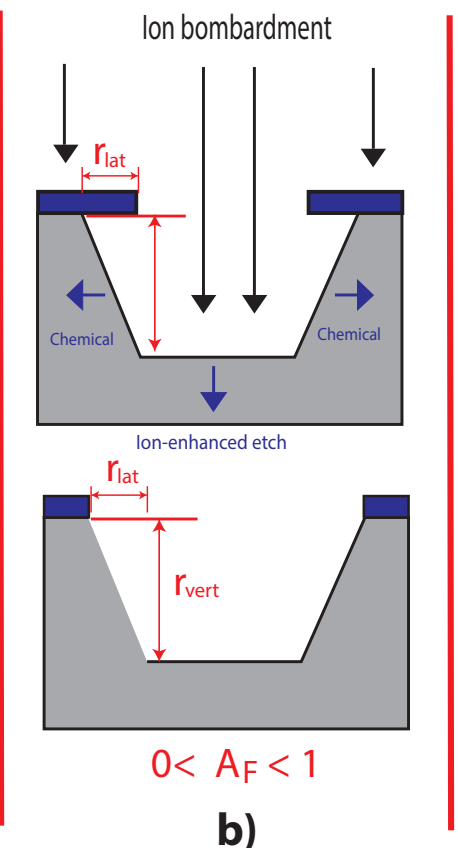

b)

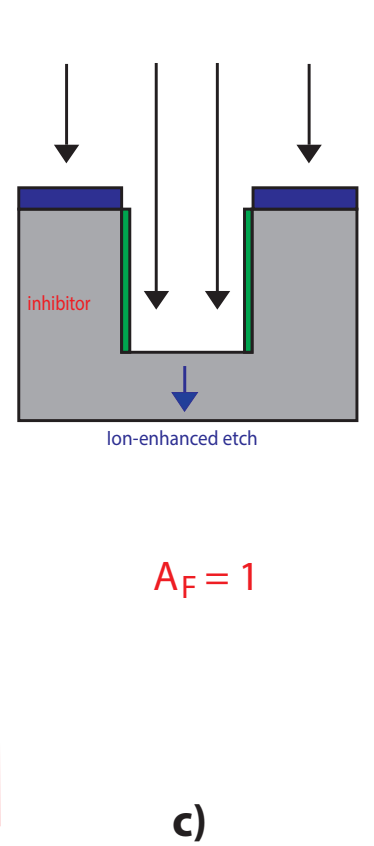

c)

FIG. 3. Profile changes as function of the silicon etching process condition: a) isotropic etch, b)directional etch and c) vertical etch .

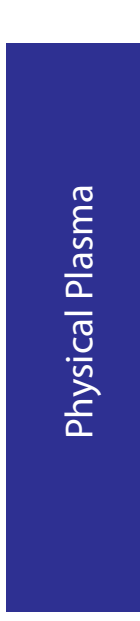

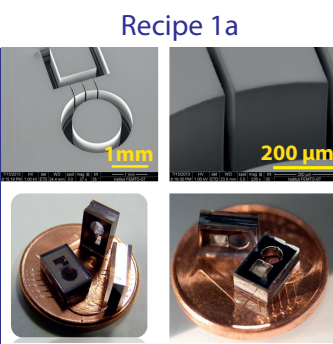

Atomic clock

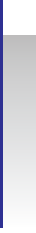

Recipe 2
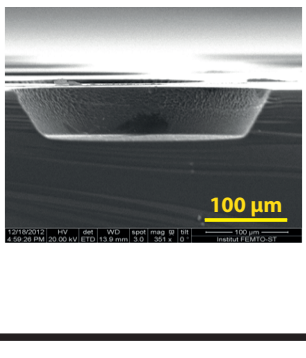

Directional etch

Anisotropic etch
Recipe 3

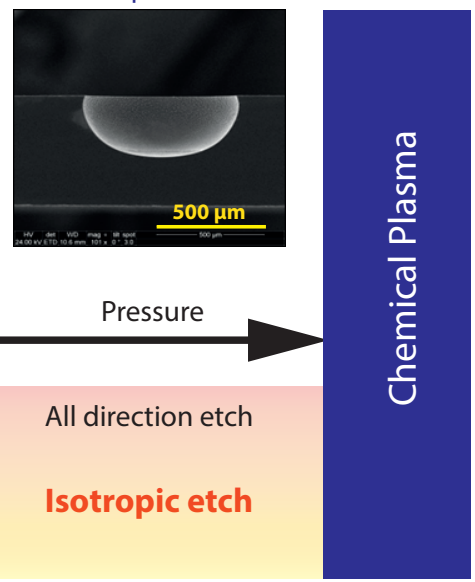

FIG. 4. Illustration of typical result for pulsed-mode DRIE: physical plasma toward chemical plasma. 


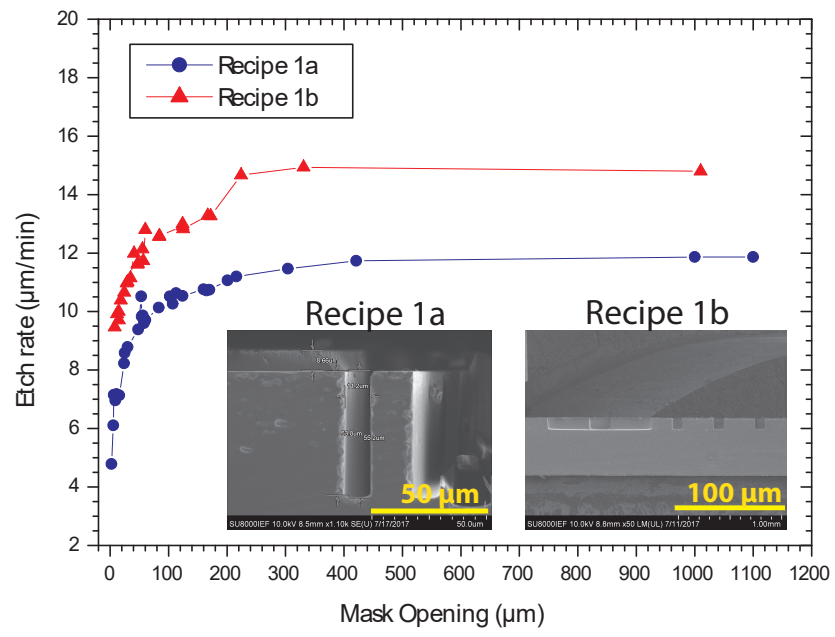

FIG. 5. ARDE in silicon wafer. Inset : SEM microgrpahs Side view of several DRIE trenches made with different etching widths: a larger width induces a higher etching depth.

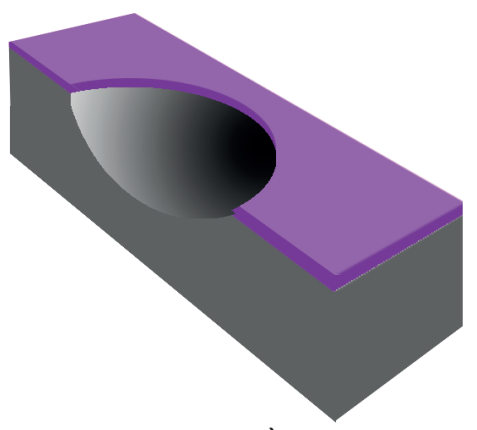

a)

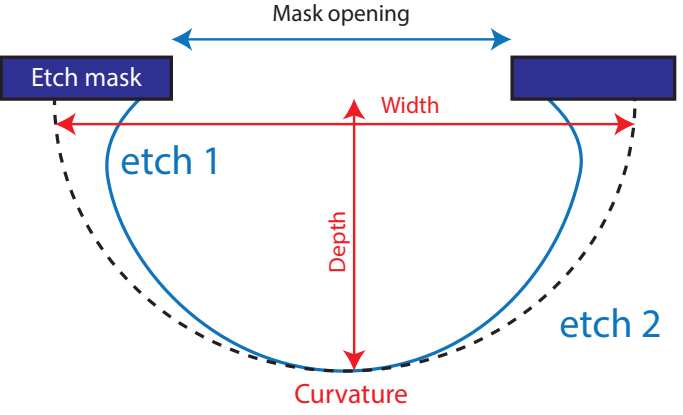

b)

FIG. 6. The etching geometry representation of the raceway profile during an ideal isotropic etch process: a) 3D design and b) geometric parameters of interest are highlighted in $2 \mathrm{D}$ view. 


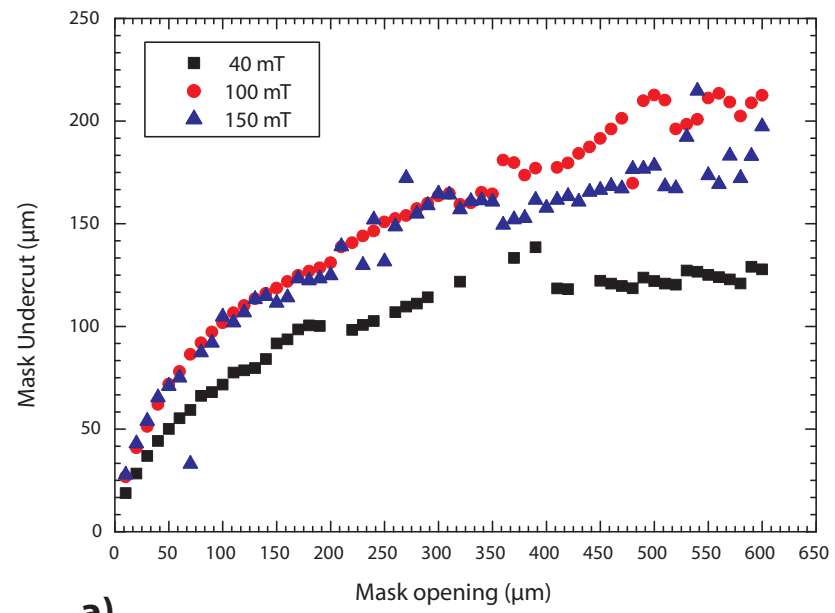

a)

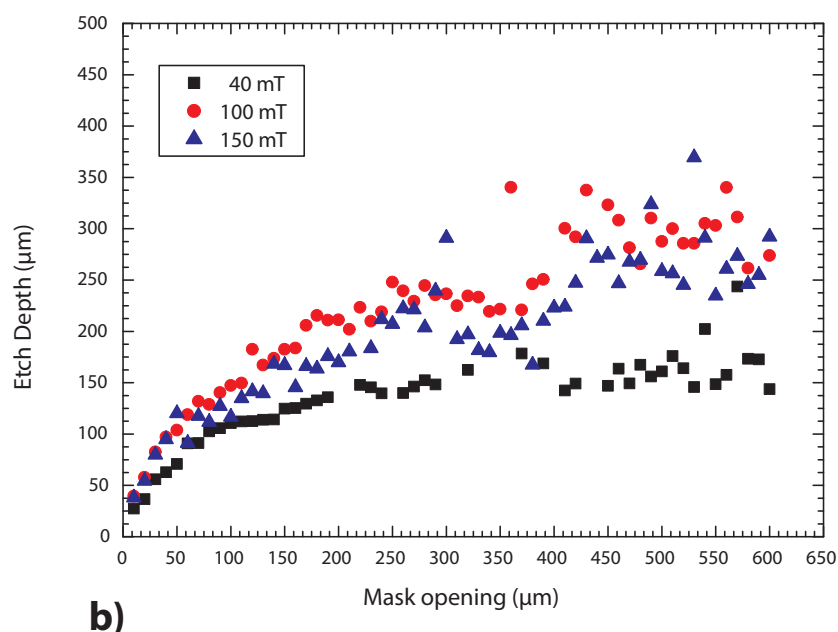

FIG. 7. Silicon isotropic etching profiles as a function of plasma pressure: (a) Mask undercut, (b) Etch depth. The temperature substrate, $S F_{6}$ flow rate and time were $0 \mathrm{deg} \mathrm{C}, 500 \mathrm{sccm}$, and $900 \mathrm{~s}$ respectively.

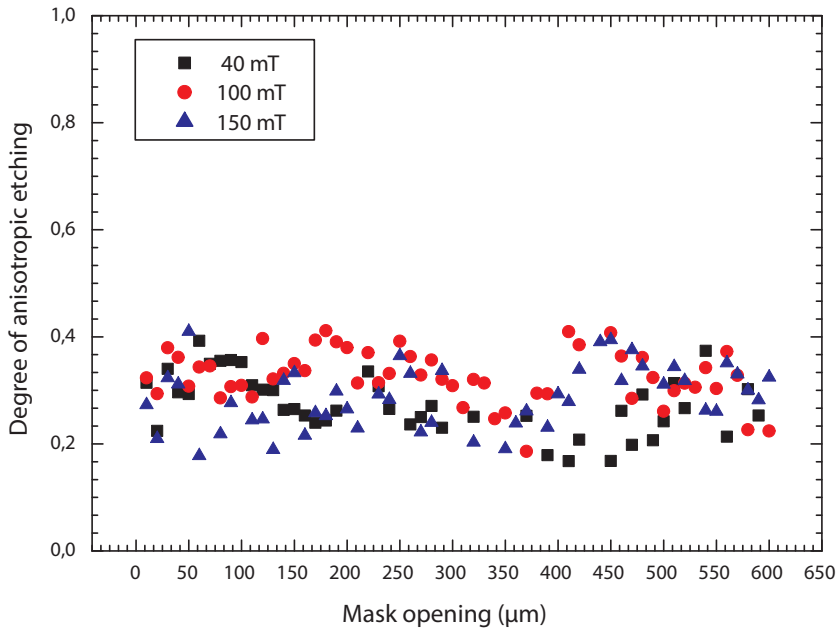

FIG. 8. Degree of anisotropic etching as a function of pattern size with different plasma pressures. 

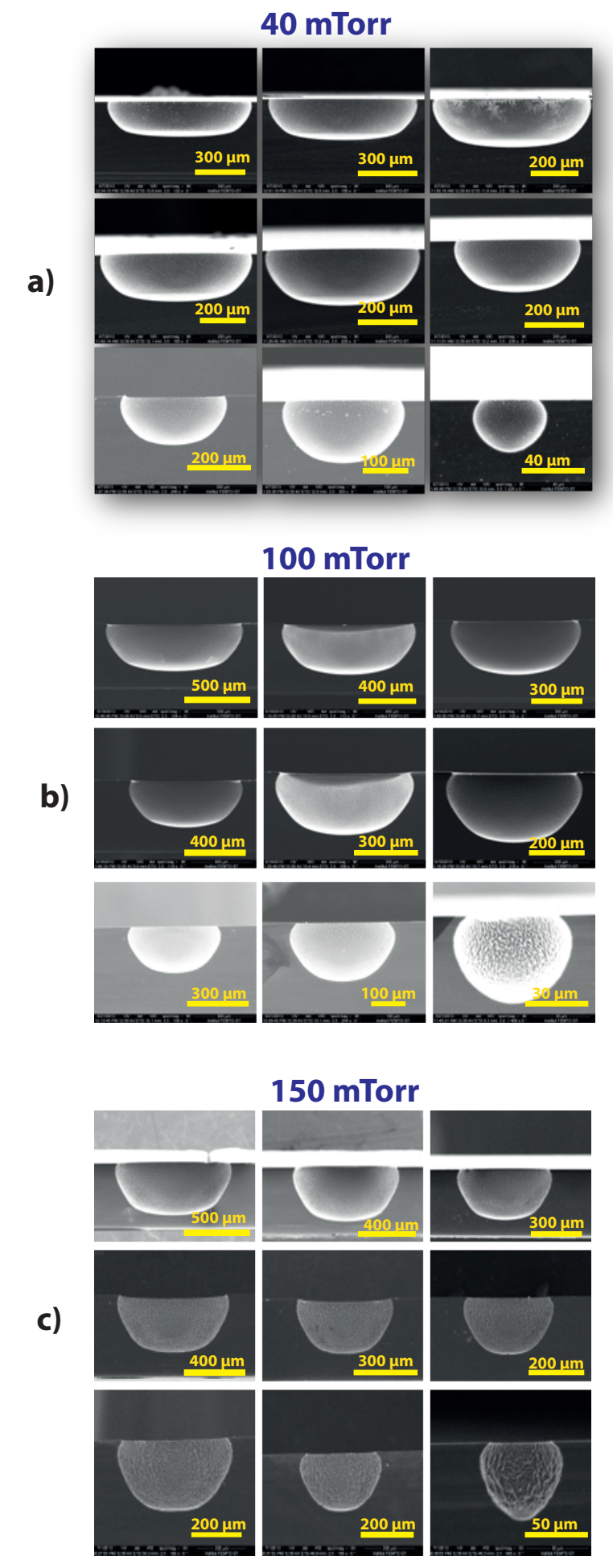

FIG. 9. Cross sectional SEM micrograph of bulk-etched cavities in a $\langle 100\rangle$ Si substrate for different chamber pressure. The parameters of the etching process were : Temperature $=0^{\circ} \mathrm{C}$, coil power $=2000 \mathrm{~W}$, platen power $=20 \mathrm{~W}, \mathrm{SF}_{6}=500 \mathrm{sccm}$ standard cubic centimeters per minute (sccm) at pressure : a) 40 mtorr, b) $100 \mathrm{mtorr}$ and c) 150 mtorr as indicated. 

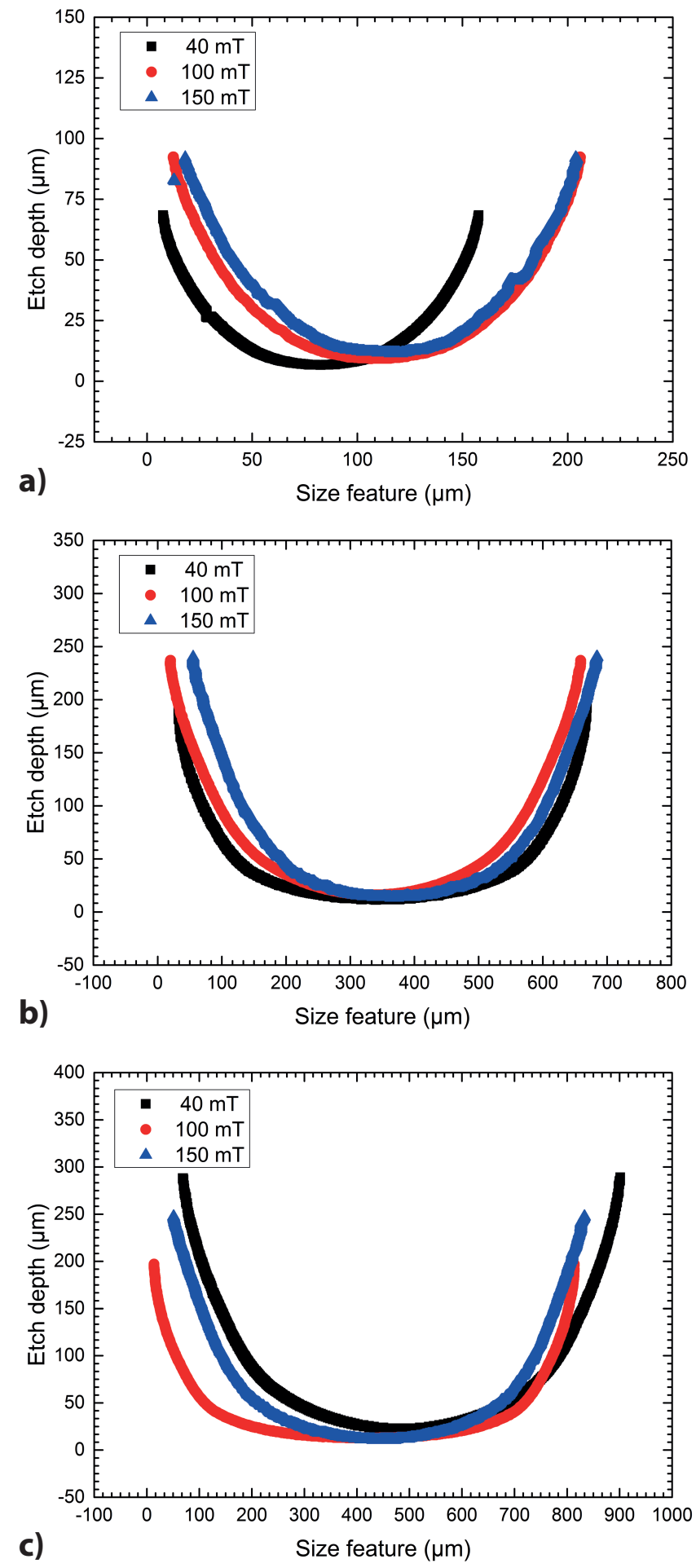

FIG. 10. Comparison of the cross-sectional geometries obtained by isotropic etching for $900 \mathrm{~s}$. 


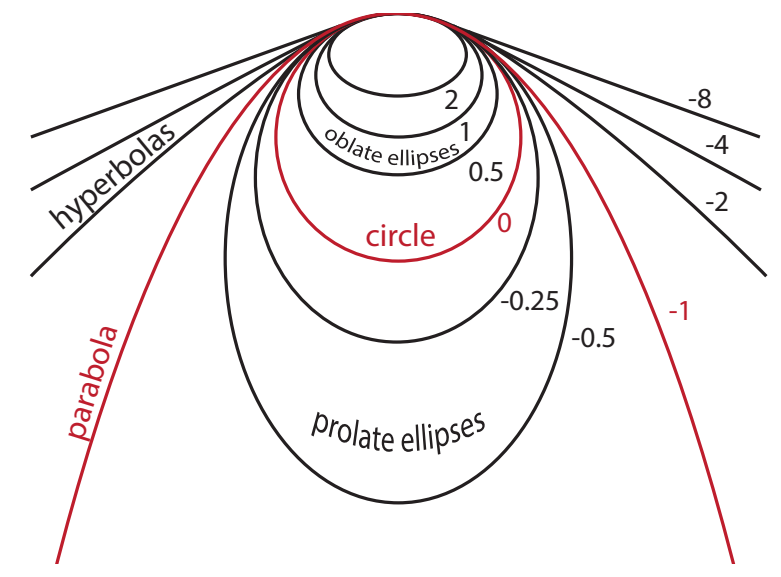

FIG. 11. Profiles of conic sections with k parameter indicated. 


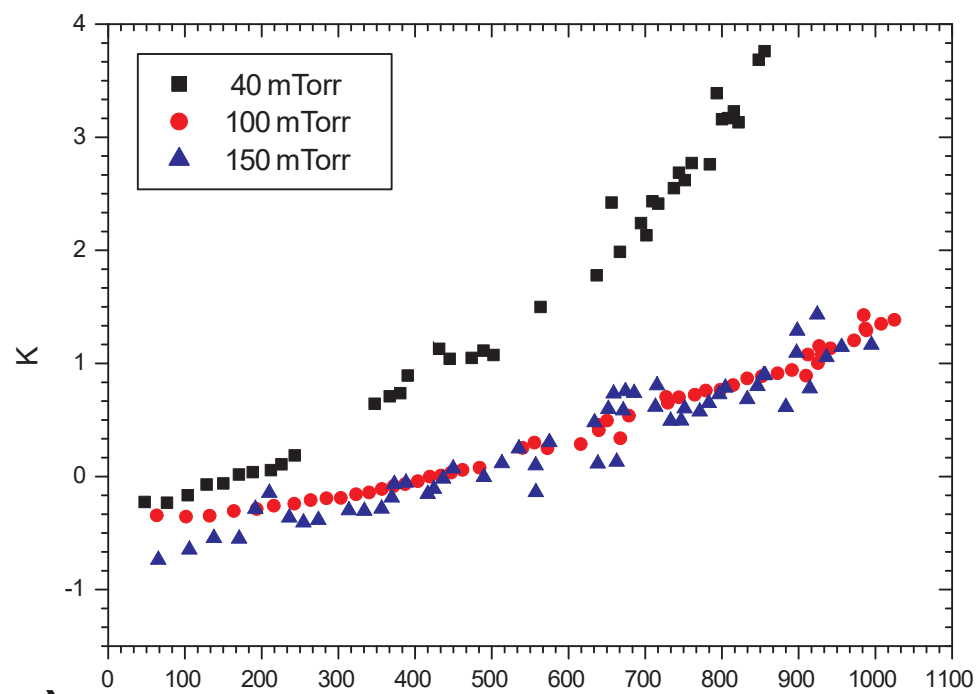

a)

Size aperture $(\mu \mathrm{m})$

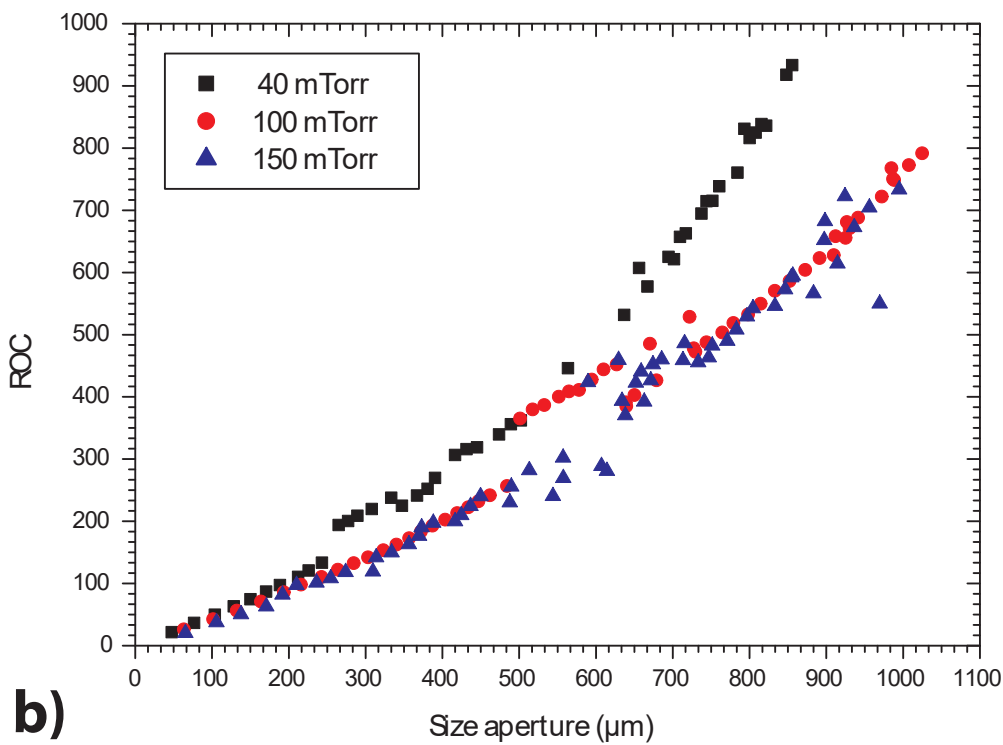

FIG. 12. Conic constant of the specific size aperture. 